\title{
Metodologias ativas no internato de enfermagem: percepção dos docentes
}

\section{Active methodologies in nursing internship: perceptions of teachers}

\author{
${ }^{1}$ Carolina Favarão Marton carol_favarao@hotmail.com \\ ${ }^{2}$ Simone Domingues Garcia \\ ${ }^{3}$ Marli Terezinha Oliveira Vannuchi \\ ${ }^{4}$ Thayane Roberto Simões \\ ${ }^{5}$ Beatriz Silva Ignotti
}

\section{RESUMO}

Estudo descritivo qualitativo, com o objetivo de desvelar a percepção de docentes sobre as metodologias ativas utilizadas durante o internato de Enfermagem. Participaram sete docentes que responderam a seguinte questão: Como os docentes avaliam o uso de metodologias ativas durante as aulas teóricas do internato de enfermagem? Os resultados geraram cinco categorias: o interno na busca do conhecimento: teoria vinculada à prática; as metodologias ativas na visão do docente; papel do docente nos encontros teóricos do internato de enfermagem; potencialidades e fragilidades na utilização das metodologias ativase, o crescimento do interno ao longo do internato: olhar do docente. Os resultados demonstraram que os docentes identificam-se com o uso das metodologias ativas por considerar que o método oportuniza uma formação centrada no aluno, oferecendo maior autonomia e capacidade de tomadas de decisões. Concluiu-se que o método oferece mudanças significativas na formação de novos enfermeiros, gerando profissionais críticos e reflexivos.

Palavras-chave:Educação em enfermagem. Estudantes de enfermagem; Internato não médico.

\begin{abstract}
Qualitative descriptive study aimed at uncovering the perception of teachers on active methodologies used during the boarding of Nursing. Participants were seven teachers who responded to the question: How teachers evaluate the use of active methodologies during lectures from boarding nursing? The results generated five categories: domestic in pursuit of knowledge: theory linked to practice; active methodologies in view of the teacher; role of the teacher in theoretical meetings boarding nursing; strengths and weaknesses in the use of active methodologies and internal growth throughout the internship: look at the teacher. The results showed that teachers identified with the use of active methods on the grounds that the method gives opportunity training learner-centered, offering greater autonomy and capacity for decision making. It was concluded that the method offers significant changes in training new nurses, generating critical and reflective practitioners.
\end{abstract}

Keywords: Education. Nursing. Students. Nursing. Internship. Nonmedical.

\footnotetext{
Universidade Estadual de Londrina, UEL.

Universidade Estadual de Londrina, UEL.

Universidade Estadual de Londrina, UEL.

Universidade Estadual de Londrina, UEL.

Universidade Estadual de Londrina, UEL.
} 


\section{INTRODUÇÃO}

A educação na área da saúde é influenciada por diferentes mudanças tecnológicas, que apresentam avanços significativos na disponibilização das novas informações, conhecimentos e metodologias de ensino. É preciso que essas inovações acompanhem os novos profissionais, proporcionando uma formação crítica aos alunos, diferente dos métodos antigos com repetição de conteúdo pré-estabelecido onde não há estímulo a criatividade dos discentes (OLIVEIRA; PRADO; KEMPFER, 2014).

Ao citar a Política Nacional de Educação em Saúde disponibilizada pelo Ministério da Saúde, destacamos pontos importantes como o conceito ampliado de saúde trabalhado por meio das metodologias ativas de ensino-aprendizagem. A política considera o aprendizado no ambiente de trabalho como eixo estruturante do processo, integrando os docentes com os enfermeiros dos serviços na construção de uma formação integradora (GARCIA; VANNUCHI, 2014).

Como proposta de método diferenciado, as metodologias ativas de ensino e aprendizagem configuram-se em uma possibilidade de mudança, na medida em que assumem uma dinâmica de trabalho aberta, coletiva, integradora e facilitadora da aprendizagem. O discente se responsabiliza pelo seu processo de aprendizado, valorizando suas vivências e a realidade do cenário de saúde, aproximando sua formação e suas expectativas ao oferecido pelo sistema atual (OLIVEIRA; PRADO, 2014).

As metodologias ativas foram citadas em estudo Canever et al. (2014) como elemento de destaque durante a graduação por influenciar de forma positiva e transformadora a percepção da realidade, considerando que somente a visão crítica não é suficiente para modificar os problemas, sendo o método de ensino e a educação oferecida o grande propulsor de mudanças sociais e transformação concreta da realidade, ou seja, é preciso dispor de educadores/docentes preparados e capacitados para proporcionar uma formação diferenciada aos novos enfermeiros inseridos no mercado de trabalho.

O docente inserido na utilização das metodologias ativas atua como professor-facilitador, tornando-se fundamental para que o aluno visualize a importância da sua atuação no cenário da saúde, e consequentemente desenvolva-se com princípios éticos, dedicação, comprometimento e compreensão da complexidade da futura profissão (CANEVER et al., 2014).

O internato de enfermagem ou estágio profissionalizante corresponde ao estágio supervisionado do curso, que de acordo com as Diretrizes Curriculares Nacionais deve ocorrer no último ano da graduação, iniciando-se no primeiro semestre e finalizando no segundo semestre do ano letivo. O internosupervisionado pelo docente atua durante 26 semanas, o correspondente a $20 \%$ da carga horário total do curso, sendo metadedo tempo em unidades hospitalares de instituições de alta e média complexidade e a outra metade nas Unidades Básicas de Saúde. Os encontros teóricos são baseados na utilização das metodologias ativas e ocorrem concomitantemente a prática, realizando assim a práxis do internato de enfermagem (GARCIA; VANNUCHI, 2014).

Durante os encontros teóricos do internato de enfermagem os docentes oportunizam momentos de associação entre a prática do aluno com os temas gerenciais estudados, valorizando o aprender a aprender na busca por fatores explicativos e possíveis soluções para os problemas compartilhados em grupo. Trata-se de um momento de grande enriquecimento vivenciado pelos docentes, que participam do desenvolvimento do aluno juntamente com o grupo e estimulam o compartilhar dos novos conhecimentos formados nos campos de prática de cada interno (GARCIA; VANNUCHI, 2014).

Essa forma de ensinar e aprender se utiliza dos conhecimentos prévios do estudante, que somados aos conhecimentos adquiridos resultam na construção de novos conhecimentos e saberes, demonstrando ao docente presente o desenvolvimento dos futuros enfermeiros (GARANHANI et al., 2013). 
Com isso, afirma-se que para formar enfermeiros transformadores é preciso a participação efetiva de docentes engajados, envolvidos com os métodos de ensino e que saibam proporcionar um meio propício de compartilhamento de novos conhecimentos entre os alunos. Os docentes são peças vitais que participam antes, durante e depois da realização do internato de enfermagem, ao considerar que o processo inicia-se com o planejamento até a saída do aluno para o mercado de trabalho.

Assim este trabalho teve como objetivo desvelar a percepção dos docentes sobre as metodologias ativas utilizadas durante as aulas teóricas do internato de enfermagem da Universidade Estadual de Londrina.

\section{TRAJETÓRIA METODOLÓGICA}

O estudo utilizou a pesquisa descritiva de abordagem qualitativa orientada pela teoria da conscientização, onde se defende uma pedagogia crítica com análise política no cenário vivenciado, em contraposição a educação de depósito do conhecimento, lutando na busca por estudantes que criam sua própria educação, fazendo assim seu próprio caminho (FREIRE, 2001). A análise qualitativa valoriza o conhecimento que tem como matéria prima opiniões, crenças, valores, representações, relações e ações humanas e sociais sob a perspectiva dos atores (MINAYO, 2012).

Os docentes foram contactados no Centro de Ciências da Saúde (CCS), que compõe um dos nove centros de estudos da Universidade Estadual de Londrina e contempla o curso de enfermagem. Foi apresentado o objetivo do estudo e a forma como seria realizado. A participação de todos foi voluntária. Optaram por participar sete docentes que atuaram em aulas teóricas do internato do curso de enfermagem no ano de 2012.

Preocupou-se em entrevistar tanto docentes que atuavam no internato em saúde coletiva, quanto docentes do internato hospitalar, para assim, obter resultados abrangentes e condizentes com a realidade que o estudante vivencia nesta última etapa da graduação. Destes, três teorizaram conteúdo da área hospitalar e quatro conteúdos na área de saúde coletiva.

Para proceder as entrevistas utilizou-se da seguinte questão norteadora: como os docentes avaliam o uso de metodologias ativas durante as aulas teóricas do internato de enfermagem?

A seleção dos entrevistados ocorreu conforme a disponibilidade dos mesmos e suas falas foram identificadas com a letra "D" para garantir o anonimato dos docentes e enumeradas de acordo com a sequência das entrevistas.

Utilizou-se análise de conteúdo que consiste em um conjunto de técnicas de análise das comunicações, que por meio de procedimentos sistemáticos e objetivos de descrição do conteúdo das mensagens, permitem a conclusão de conhecimentos relativos e recepção destas mensagens, levando a construção de categorias por meio de depoimentos (MINAYO, 2012).

Este processo se dá por etapas de análise de dados, divididas em três fases: 1) pré-análise (organiza o material, sistematizando as ideias iniciais); 2) exploração do material (definição de categorias e unidade de significação) e 3) tratamento dos resultados, inferência e interpretação (MINAYO, 2012).

A pesquisa possui aprovação do Comitê de Ética em Pesquisa envolvendo seres humanos da Universidade Estadual de Londrina com CAAE: 0165.0.268.000-11. 


\section{RESULTADOS E DISCUSSÃO}

Ao analisar o conteúdo das entrevistas obtiveram-se cinco categorias, denominadas: O interno na busca do conhecimento: teoria vinculada à prática; As metodologias ativas na visão do docente; Papel do docente nos encontros teóricos do internato de enfermagem; Potencialidades e Fragilidades na utilização das metodologias ativas e, $\mathrm{O}$ crescimento do interno ao longo do internato: olhar do docente.

\section{1 interno na busca do conhecimento: teoria vinculada à prática}

Durante a aprendizagem do interno de enfermagem é essencial que este, além de buscar o conhecimento por meio de leituras científicas e sínteses de textos, aprenda a vincular a teoria à prática vivenciada nos serviços de saúde onde está inserido.

As falas abaixo mostram o quanto os docentes acreditam que o entrelaçamento da teoria e da prática é vital para a formação desse futuro enfermeiro:

A teoria vem justamente para embasar esse processo de vivência prática.(D5)

Essa relação teórico-prático é muito forte no internato, é trazer o encontro das vivências práticas que eles têm com a questão teórica, para que não se torne uma questão muito idealista (D6)

É sempre o novo sendo ancorado naquilo que ele já conhece, é sempre a teoria ancorada em coisas que tenham sido vivenciadas na prática. (D4)

Se ele não fizer essa junção do aprofundamento teórico com o que ele vê lá na prática, continua teórico.(D7)

Conforme exposto nas falas é fundamental que a prática esteja atrelada à teoria, para que assim o estudante consiga desenvolver a capacidade crítica e reflexiva sobre a realidade vivenciada no internato.

Afirma-se que sem a práxis seria impossível conseguir superar contradições, representada pela presença do possuidor do conhecimento com o que atua, e assim os homens não conseguiriam transformar o mundo por meio do conhecimento. É durante a práxis que o saber torna-se um dos elementos que utilizamos no exercício da profissão de enfermagem, com a ação baseada na competência, persistência e disponibilidade para agir (FREIRE, 2005).

A relação entre teoria e prática deve ser desenvolvida simultaneamente, de modo a se tornar uma unidade indissolúvel, na qual uma não se estabeleça sem a outra, tanto a prática não deve ser a aplicação sem a teoria quanto a teoria não é concretizada sem a prática. Nessa proposta, o perfil do profissional esperado abrange a responsabilidade política, ética e humanista, que através de suas ações, torna-se um agente de transformação social.

Com isso é preciso pensar não somente nas potencialidades encontradas na assimilação da teoria com a prática, mas também nos desafios diários dispostos com o processo do cuidado, como a vivência da dor, da perda, das situações de estresse, sobrecarga, entre outros. Os estudantes quando se expressam revelam seus valores, crenças, vivências pessoais e sentimentos que nem sempre estão definidos frente ao incerto. Estes fatores devem ser do conhecimento do professor, possibilitando que o mesmo elabore um plano de ação que vise minimizar o sofrimento dos estudantes contribuindo para o processo de amadurecimento dos mesmos (ALVES; COGO, 2014).

Neste contexto a seguinte fala demonstra a preocupação do docente em relação à identificação das fragilidades do estudante: 
Tem que saber identificar suas fragilidades, e buscar saná-las [...] e essa busca deve ser constante, isso é o mais importante [...] mais do que achar que ele sabe tudo, é que ele entenda essa importância do aprender a aprender, de ser agente do próprio conhecimento.(D7)

Houve clareza no exposto pelo docente que o conhecimento adquirido pelos internos o potencializa na superação dos seus desafios através do aprendizado contínuo.

Os internos passam por uma transição de futuro profissional que exige dos mesmos o entendimento que a prática profissional é muito mais do que estudar patologias, medicamentos ou procedimentos. Trata-se, na verdade, de entender e respeitar as fragilidades humanas (ALVES; COGO, 2014).

Diversos são os sentimentos vivenciados dentro de ambientes hospitalares e também em outros serviços de saúde destinados ao atendimento dos pacientes. Afirma-se que pouco é o tempo disponível entre a ação realizada e o diálogo necessário para a reflexão, sendo essas situações causadoras de conflitos ou sofrimentos acadêmicos (ALVES; COGO, 2014).

Referente ao processo de aprendizado e reflexão é preciso haver um cenário propício para a observação da realidade, permitindo que essa vivência se concretize em novos conhecimentos e superações. Considera-se que é oportuno exigir um modelo de ensino atualizado conforme as mudanças apresentadas, com um ensino que desperte no estudante a responsabilidade de atualizar-se, de buscar informações e de manter-se atento às mudanças (OLIVEIRA; CAMPOS, 2013).

A responsabilidade pela busca do conhecimento constante se faz tão necessário quanto o local de prática, pois com o estudo prévio, o estudante vem mais preparado para o campo de trabalho e se sente mais seguro em suas intervenções. (OLIVEIRA; CAMPOS, 2013).

Além dos momentos teóricos que ocorrem semanalmente o interno é responsável por realizar uma reflexão semanal sobre sua prática como parte constituinte do portfólio, importante ferramenta de trabalho que envolve todo o desenvolvimento teórico do aluno no decorrer do internato. A intenção dessas reflexões é fazer com que o interno reflita de maneira crítica a sua prática e não apenas a vivencie.

O portfólio é um compilado de atividades e trabalhos realizados pelo estudante, que tem como objetivo provocar reflexão e análise da situação correlacionando teoria e prática. Ao longo da confecção o estudante deve se utilizar de pensamento crítico, criatividade, auto avaliação, capacidade de explanação, solução de problemas, desenvolvimento de projetos e formulação própria de objetivos para o estudo (OTRENTI, 2011).

\section{2 As metodologias ativas na visão do docente}

Em relação às metodologias ativas, as falasabaixo demonstrama percepção do docente sobre a sua utilização em sala de aula:

Eu acho que as metodologias ativas que usamos é nesse sentido, de propiciar que o aluno busque o conhecimento, que ele faça suas leituras, que ele traga pontos para a discussão, que ele faça a ligação teórico-prática.(D2)

A metodologia ativa se não tiver uma intencionalidade de onde você quer chegar, você se perde.(D3)

As falas expõe claramente a necessidade do professor provocar as questões norteadoras em busca de conteúdos para compreensão da realidade e fundamentação da prática. A partir disto, o aluno consegue desenvolver consciência crítica além de estabelecer relação entre as informações anteriores e a experiência atual (PARANHOS; MENDES, 2010). 
Considera-se que o papel de educador e de educando possuem igual importância no processo educativo, portanto não devem ser impositivos e analisados isoladamente fora de uma realidade que não seja vivenciada pelos atores envolvidos (FREIRE, 2005).

Com a utilização de metodologias ativas pelos docentes, procura-se trazer situações da realidade e incentivar a discussão a fim de solucionar um problema. Enquanto se discute, percebe- se a necessidade de estudar mais sobre o assunto, levando a real intenção de se propor este método. Pode- se utilizar de várias ferramentas para chegar à solução do problema possibilitando também a visualização do mesmo por ângulos diferentes e quando realizada em grupo, até por pontos de vista diferentes.

A fala seguinte demonstra como o docente visualiza e estimula a busca pelo conhecimento e o desenvolvimento do interno:

O aprendizado do aluno depende muito, se ele leu ou não o texto [...] além do fato de que temos que levantar o que um aluno já sabe e estimular a curiosidade para um aprofundamento [...] sistematizar o que o aluno foi capaz de aprender sozinho e com a opinião de um grupo que também fez pesquisas sobre o mesmo tema.(D1)

[...] Dependendo do tema você vai lançando mão de diferentes estratégias que possam chamar a atenção e possam ajudar a recuperar essas experiências.(D4)

Destaca-se a necessidade de esforço e dedicação do aluno, para que o mesmo consiga planejar-se para além de adquirir novas experiências vivenciadas, consiga criar uma rotina de estudos que o fundamente para as situações diversas.

Em estudo Canever et al. (2014) destaca-se a relação afetiva com o professor, o qual auxilia o aprendizado acadêmico e estimula o aluno a dedicar-se, considerando que o conhecimento modifica-se rapidamente e o profissional precisa manter-se atualizado até por um imperativo ético do seu exercício profissional.

Assim, o professor assume o papel de orientador, facilitador e mediador da aprendizagem e deve buscar despertar no estudante o seu potencial de intervenção na realidade. Para que isso se estabeleça é importante que o docente esteja disponível para acompanhar o estudante neste processo, onde podem surgir situações imprevistas e desconhecidas (GARANHANI, 2013).

\section{3 Papel do docente nos encontros teóricos do internato de enfermagem}

A fala a seguir demonstra como o docente visualiza seu papel enquanto utilizador das metodologias ativas:

O aluno precisa ser orientado, direcionado, então não é por que ele é ativo que faz tudo por conta, por si só. O professor tem um papel muito importante de condutor, ele precisa planejar todas as atividades, precisa ver tudo o que está acontecendo [...] Porque às vezes tem um senso comum de achar que metodologia ativa o professor não faz nada [...] a metodologia ativa exige uma disponibilidade, uma organização muito maior desse professor.(D6)

O planejamento e a organização são a essência do dia-a-dia dos docentes, que necessitam dedicar-se muito além da sala de aula. Ao considerar os estágios curriculares o planejamento deve ser visto como fator primordial para a construção de um processo de ensino-aprendizagem cumprindo com as exigências de atenção a saúde. Para que isso ocorra é preciso valorizar os conhecimentos acadêmicos, respeito à experiência do mundo do trabalho e atenção as demandas dos usuários dos serviços (RODRIGUES; TAVARES, 2012). 
Planejar envolve reflexões, tomada de decisão sobre a ação, previsão de necessidades e de racionalização no emprego dos meios (materiais) e profissionais disponíveis, visando a concretização de objetivos (RODRIGUES; TAVARES, 2012).

Pode-se definir o planejamento também como forma de discussões oportunizadas aos atores envolvidos, considerando que diálogo não é um produto histórico, é a própria história sendo construída em um movimento constitutivo da consciência, que se abrindo para a infinitude vence as fronteiras impostas (FREIRE, 2001).

A categoria seguinte demonstra que o caminho percorrido na utilização das metodologias ativas possui desafios e superações importantes de serem destacadas.

\section{4 Potencialidades e fragilidades na utilização das metodologias}

Quando questionados sobre como era trabalhar com metodologias ativas no internato, alguns docentes citaram:

É esse o caminho, às vezes temos que dar um passo atrás por ter alguma dificuldade [...] eu acho que sempre cabe aperfeiçoar [...] mas acho que não voltaremos para o mesmo lugar [...] porque a gente já tem isso impregnado na gente [...] eu não consigo me ver mais trabalhando de outra forma.(D2)

Eu tenho certeza que voltar ao tradicional é impossível, a gente não aprende dessa forma, quando a coisa chega pronta [...] eu vejo que não tem outra saída e os resultados são muito bons, a gente percebe que é diferente.(D7)

Os docentes deixam claro o desafio diário vivenciado com o uso de metodologias ativas e a importância de refletir sobre quais seriam as possibilidades de aprimoramento do método adotado.

Para que ocorra o progresso do ensino, é importante que estudantes e professores reconheçam e compreendam quais são as dificuldades e facilidades desse processo, para que assim seja possível gerar o aprendizado significativo (SEMIN; SOUZA; CORREA, 2009).

A realidade coloca o desafio não só da elaboração de projetos pedagógicos e desenhos curriculares, mas de uma prática curricular que possibilite uma formação de enfermeiros comprometidos com o enfrentamento dos graves problemas de saúde da nossa sociedade, o que significa não perder a perspectiva da integralidade da atenção, da equidade, da eficiência e da eficácia (SILVA et al., 2010).

Entre os desafios que se destacam estão o desenvolvimento e avaliação das competências e das habilidades, dos conteúdos essenciais, das práticas de estágios e atividades complementares. É preciso aprofundar as discussões relacionadas ao desenvolvimento da competência de trabalhar a parte prática do conhecimento adquirido em um processo formativo de verdadeiros cidadãos questionadores do processo pedagógico e funcional do sistema de saúde (SILVA et al., 2010).

Com isso, representa um significativo avanço na formação profissional e na superação de desafios impostoso uso de metodologias ativas, que contribuem no desenvolvimento do modo de cuidado mais amplo e integral (MARIN, 2010).

E entre potencialidades e fragilidades, é possível perceber que a proximidade do conhecimento com a realidade é imprescindível, porque, na medida em que o homem integra-se no seu contexto de vida, reflete sobre ela e gera respostas aos desafios que se lhe apresentam (FREIRE, 2005). Finaliza-se com a categoria abrangendo o desenvolvimento do aluno com a prática do internato na percepção do docente. 


\section{5 O crescimento do interno ao longo do internato: olhar do docente}

Ao longo das entrevistas abordaram-se o quanto o internato pode mudar o estudante,como pode ser observado nas falas a seguir:

É visível o quanto ele fica diferente do começo para o fim do internato [...] quando você o vê no primeiro dia e o vê no último dia [...] são duas pessoas diferente.s (D4)

Acho que o internato tem uma característica importante que favorece a metodologia ativa, que é o aluno mais maduro, que é o aluno mais experiente [...] ele está aberto a aprender porque sabe que é a última chance de aprender dentro da faculdade, isso favorece a consolidação dos conceitos.(D1)

O processo de educação focado no estudante, por meio de metodologias ativas, permite que o mesmo possa amadurecer, adquirindo autonomia em níveis crescentes, proporcionandoa formação de profissionais mais preparados e aptos ao trabalho em equipe, a integralidade da atenção e a constante busca do aprendizado enquanto profissional (SILVA; MIGUEL; TEIXEIRA, 2011).

Há também uma mudança nítida no caminhar do interno em relação aos seus conceitos pré-existentes, substituindo-os por ideias mais pertinentes com a realidade e mais sólidas, proporcionando a instalação de novos conhecimentos e oportunidades ${ }^{(17)}$. (Moraes, 2013).

Entre o crescer e o florescer do aluno enquanto ator principal e o docente, enquanto peça chave, há a correlação de educandos e educadores, que precisam desde o início da experiência formadora assumir-se como sujeitos da produção do saber, convencendo-se que ensinar não é transferir conhecimento, mas criar a possibilidade para a sua produção ou construção. Com isso, assumem-se como seres pensantes, comunicantes, transformadores, criadores, realizadores de sonhos, e capazes de transformarem o mundo a sua volta (FREIRE, 2001).

Logo, o estabelecimento da responsabilidade pelo seu próprio conhecimento, descreve o quanto o internato de enfermagem pode ajudar o estudante em seu processo de amadurecimento e aprendizagem, remetendo-o a uma imagem de um futuro enfermeiro crítico e reflexivo frente ao serviço de saúde.

Mostrar o caminho do aprendizado relevante, demonstrando aos internos o quanto eles podem ser grandes e significativos no sistema de saúde representa importante estímulo aos docentes, por considerarem que ao empoderar os alunos, os mesmos compreendem que por maior que seja o aprendizado adquirido, não estão sozinhos na busca pela qualidade nos serviços, pois os docentes que hoje transferem conhecimentos essenciais eternizam-se dentro de cada ação efetiva de seus ex-alunos.

\section{CONCLUSÃO}

O estudo oportunizou conhecer importantes potencialidades nas percepções de docentes que utilizam as metodologias ativas, não somente durante a teorização, mas na práxis do internato de enfermagem.

Foi possível identificar o quanto as metodologias ativas estão difundidas entre os docentes, visto que mesmo diante dos desafios enfrentados os mesmos não se imaginam mais utilizando o método tradicional, por considerar que nossa realidade já não corresponde mais ao docente como principal detentor do conhecimento.

Constatou-se que os encontros teóricos potencializam situações vivenciadas nas realidades dos campos de estágios, tornando mais fidedigno o interesse pelo conteúdo e consequentemente levando o interno ater mais interesse na pesquisa dos temas trabalhados. 
O docente revelou-se como mediador e não transmissor de conteúdos prontos, comportamento considerado fundamental no método para tornar o estudante mais ativo e responsável pelo seu conhecimento. Porém, é claro entre os docentes que o estudante deve ter ciência que esse processo só se realiza com sucesso quando os mesmos se responsabilizam pela buscado conhecimento.

Com isso, para que esta metodologia mantenha a efetividade em sua realização, é imprescindível que professores e alunos estejam envolvidos com o processo e que realmente os executem com propriedade, responsabilidade e focados na qualidade da formação.

Por fim, desvela-se na percepção dos docentes que o aluno que constrói o seu conhecimento por meio de metodologias ativas torna-se um profissional capaz de enfrentar os desafios que emergem diariamente no cenário de saúde nacional com competência, habilidades e atitudes necessárias.

\section{REFERÊNCIAS}

OLIVEIRA, S. N.; PRADO, M. L.; KEMPFER, S. S. Utilização da simulação no ensino da enfermagem: revisão integrativa. REME: Revista Mineira de Enfermagem, Belo Horizonte, v. 18, n. 2, p. 487-495, 2014.

GARCIA, S. D.; VANNUCHI, M. T. O. O internato de enfermagem da Universidade Estadual de Londrina: conquistas e desafios. Londrina: INESCO, 2014.

CANEVER, B. P. et al. Processo de formação e inserção no mercado de trabalho: uma visão dos egressos de enfermagem. Revista Gaúcha de Enfermagem, Porto Alegre, v. 35, n. 1, p. 87-93, 2014. Disponível em: <http:// seer.ufrgs.br/index.php/RevistaGauchadeEnfermagem/article/view/43279/28939>. Acesso em: 20 set. 2016.

GARANHANI, M. L. et al. Currículo integrado de enfermagem no Brasil: uma experiência de 13 anos, 2013. Creative Education, Porto, v. 4, n. 12B, 66-74, 2013. Disponível em: < http://file.scirp.org/pdf/ CE_2013123015545951.pdf>. Acesso em: 15 set. 2016.

FREIRE, P. Conscientização: teoria e prática da liberdade: uma introdução ao pensamento de Paulo Freire. São Paulo: Centauro, 2001.

MINAYO, M. C. S. Análise qualitativa: teoria, passos e fidedignidade. Ciência e Saúde Coletiva, Rio de Janeiro, v. 17, n. 3, p. 621-626, 2012.

FREIRE, P. Pedagogia do oprimido. 43ª ed. São Paulo: Paz e Terra, 2005.

ALVES, E. A. T. D.; COGO, A. L. P. Percepção de estudantes de enfermagem sobre o processo de aprendizagem em ambiente hospitalar. Revista Gaúcha de Enfermagem, Porto Alegre, v. 35, n. 1, p. 102-109, 2014. Disponível em: <http://seer.ufrgs.br/index.php/RevistaGauchadeEnfermagem/article/view/42870>. Acesso em: 30 set. 2016.

OLIVEIRA, N. A. A.; CAMPOS, F. M. Tecnologia na educação: a aprendizagem da língua inglesa por meio da rede social LiveMocha. Educação, Cultura e Comunicação, Lorena, v. 4, n. 7, p. 49-62, 2013. Disponível em: <http://publicacoes.fatea.br/index.php/eccom/article/viewFile/592/422>. Acesso em: 30 set. 2016.

OTRENTI, E. et al. Portfólio reflexivo como método de avaliação na residência de gerência de serviços de enfermagem. Semina: Ciências Biológicas e da Saúde, Londrina, v. 32, n. 1, p. 41-6, 2011. 
PARANHOS, V. D.; MENDES, M. M. R. Currículo por competência e metodologia ativa: percepção de estudantes de enfermagem. Revista LatinoAmericana de Enfermagem, Ribeirão Preto, v.18, n. 1, p.109-115, 2010. Disponível em: <http://www.scielo.br/pdf/rlae/v18n1/pt_17.pdf>. Acesso em 20 set. 2016.

RODRIGUES, L. M. S.; TAVARES, C. M. M. Estágio supervisionado de enfermagem na atenção básica: o planejamento dialógico como dispositivo do processo ensino-aprendizagem. RENE -Revista da Rede de Enfermagem do Nordeste, Fortaleza, v. 13, n. 5, p. 1075-1083, 2012.

SEMIM, G. M.; SOUZA, M. C. B. M.; CORREAA, A. K. Professor como facilitador do processo ensinoaprendizagem: visão de estudante de enfermagem. Revista Gaúcha de Enfermagem, Porto Alegre, v. 30, n. 3, p. 484-491, 2009.

SILVA, M. G. et al. Processo de formação do(a) enfermeiro(a) na contemporaneidade: desafios e perspectivas. Texto Contexto Enfermagem, Florianópolis, v. 19, n. 1, p. 176-184, 2010

MARIN, M. J. S. et al.Aspectos das fortalezas e fragilidades no uso das metodologias ativas de aprendizagem. Revista Brasileira de Educação Médica, Rio de Janeiro, v. 34, n. 1, p.13-20, 2010.

SILVA, R. H. A.; MIGUEL, S. S.; TEIXEIRA, L. S. Problematização como método ativo de ensino-aprendizagem: estudantes de farmácia em cenários de prática. Trabalho Educação e Saúde, Rio de Janeiro, v. 9, n. 1, p. 77-93, 2011.

MORAES, C. F. B. Desafio SENAC: alunos no comando; estratégia de aprendizagem significativa para a formação na hotelaria. Contextos da Alimentação, São Paulo, v. 2, n. 1, p. 43-51, 2013. Disponível em: http:// www.revistas.sp.senac.br/index.php/revistacontextos/article/viewFile/403/343. 